The system has now been in use for some time. More recently, the lengthy calculations required by our system have been replaced by daily sheets of azimuth and elevation angles prepared by electronic computer for each site. However, a hand-computed system still has its uses: for calibrating mobile radar sets, and for new installations before the precomputed sheets are available.

\title{
The Gestation and Birth of my Nautical Tables
}

\author{
from S. M. Burton
}

(An Address to the Association of Navigation Schools, Grimsby, 18 May 1962)

THE imaginary question I propose to answer in this address is-how does it come about that a person with such a very ordinary sort of intellect, and certainly with no particular flair for mathematics, should be the author, or nominal author, of such an imposing publication as a volume of nautical tables?

To build up the background to the story briefly let me explain that in my training ship days I received the impression that a ship's position was found by mathematical calculations. True, we knew that sextants and chronometers were necessary instruments in the scheme of things; but they only seemed to supply certain ingredients to the calculations that ultimately produced one of the components, latitude or longitude. It was when I was consigned to a stretch of service on the North Pacific in 1927 that, for something to do, I decided to try and improve my limited understanding of astronomical navigation. In the volume of Raper's Tables which I had always used there was an appendix by the Naval Instructor William Hall which explained what was then called by the Navy 'The New Navigation', and gave four-figure cosine-versine tables for the work. It was in reading, and re-reading, and thinking about Hall's marvellously lucid explanation of the St. Hilaire process that the light suddenly burst upon me. It became revealed to me that zenith distance is the same as geographical distance; and that when you take a sight you measure your actual distance from the body in homely nautical miles. What was still more interesting was-that this must always have been the case, both before, as well as after, the invention of the chronometer.

Now, this may sound a bit trite. But let it be remembered that Sumner discovered his line in 1837 , and it was not until some seventy-odd years later that St. Hilaire realized what it was that Sumner had discovered, and suggested an obvious new angle of approach to the whole subject. St. Hilaire did not invent or suggest any new mathematical process, as far as I know. Even I, in my training ship days had been taught how to solve the 'third side direct' as the problem was then called in spherical trigonometry.

Well, this discovery quite went to my head, and I rushed around the ship metaphorically shouting Eureka and telling my navigational colleagues about the 
light I had seen. But nobody else seemed in danger of catching fire, and it was quickly obvious that my enthusiasm was going to be regarded as a proper nuisance. Nobody else wanted to be jerked out of their comfortable ruts: and jolly well weren't going to be, either. Frustrated outwardly, but smouldering inwardly, I decided to write a book about it, which seemed slightly ridiculous to me; and highly ridiculous to my colleagues : but as it became obvious that it was going to keep me silently and harmlessly occupied for the rest of that particular stretch of service, it seemed to suit everybody.

Arrived home from the Pacific with my manuscript, I approached the only practicable publishers somewhat dubiously. Make no mistake about it, I was convinced that I had written the most remarkable book since St. Hilaire's time. But I did feel that the chance of anybody else taking this view was rather improbable. I suspected that I was about to be deflated in no uncertain manner.

Well, it is now history that the unexpected happened. The publishers' adviser was Captain Charles Brown of the Royal Technical College, Glasgow, and he insisted that the book should be produced. In vain the publishers protested that they had just agreed, on his recommendation, to produce a book covering roughly the same ground. Charles Brown insisted that they'd just have to publish both.

This is where we enter upon the subject of nautical tables; for it became obvious in my conversations with the publishers that anything I said on the subject of navigation was listened to with such awed respect that it was really rather disconcerting. Normally a voluminous babbler on my pet subjects: as I noticed them eyeing the lips of the oracle expectantly, I fell to stammering and getting my words all jumbled up. But it did encourage me to lay before them a view that I (and others) had long held on the subject of nautical tables: namely, that since it was now well over 100 years since a new volume of nautical tables for general sea use had been produced, it was high time something was done about it. I said it was a curious circumstance that they, the World's greatest private nautical publishers, did not possess such a book.

This produced an immediate response. They said that they had, in fact, been thinking about it on and off for years, and, in short, now was the time. When could I start?

It is hardly an exaggeration to say that this just about scared me out of my wits. I looked on it as a job for a Board of Mathematicians and similar types. But I had already said that no new kinds of tables were needed-that it was just a matter of design, arrangement, editing, \&c., and they eagerly insisted that I was the obvious man for the job. 'The man for the job!' I felt like a man with skates under him. Anyway, as you know, I mustered the nerve to take on the job somehow, and as I became absorbed in it I built up confidence.

The complaint which I had against existing nautical tables of the time was that they were all far too voluminous; and were ill-arranged specifically for tools of navigation. I knew that the blunder ratio among navigators was high-a view which was to be so amply justified in the scientific investigation undertaken at a later date; which I am sure you will all have studied. It was my view that in any calculations connected with the navigation of a real ship, any unnecessary step, or any unnecessary figuring indulged in, increases the chances of making a mistake, and is therefore a breach of good seamanship.

Actually, I had a scheme drawn up within a matter of months. But various reasons, to be mentioned later, delayed the start of the actual setting for years: 
and during this time I had many middle watches in which I prowled up and down in the dark in a thoughtful mood turning over pros and cons in my mind. During this time many of my brightest ideas had to be whittled down or dropped altogether. Some were impracticable from the printers' point of view : others were, well - on forcibly prolonged reflection not such bright ideas. During these years I drew out and filled in by hand dozens of trial pieces of page, to study alternative arrangements.

As I have said, I had a scheme drawn up within a year, but the publishers became anxious about questions of copyright. Most people know, of course, that copyright lasts for an author's lifetime and for fifty years after his death. There is no copyright in figures, but there may be copyright in the form in which figures are presented. Not, of course, in any form ; but if the form is sufficiently ingenious to amount to an invention, then it can be copyright.

Well, the publishers seemed to think there was too happy a hunting-ground for lawyers here. They thought it possible that the reason why it was over 100 years since a new volume of nautical tables had come into being might be due to this copyright difficulty. They therefore wanted me to put every table into an original form, adequately different from anything then existing. This idea I could not accept. Where I felt sure an existing form was the best form, I insisted it must be used. For some months I lived in rooms close to the British Museum, searching up the origin of various tables: and a most interesting time it was, too.

The two tables which were chiefly causing the publishers anxiety were the Traverse Table and the table of combined natural and log haversines. The Traverse Table existed in several books, and was very old (about $175^{\circ}$ ), but I wanted someone's permission to lift the figures direct. I was not anxious to make fifty-four thousand calculations, however simple, when they were to be read in several books. In the case of the haversine table, copyright in it was claimed by Mr. Percy Davis (of Azimuth Table fame), then about ejghty years old but apparently fighting fit. He claimed that his copyright had been violated twice. Once by Norie, out of whom he got some compensation, and once by the U.S. Hydrographic Office, in Bowditch. The U.S. were not members of the Berne Copyright Convention, but their Government had always been fairly generous in these matters. They would not admit, however, that Percy's table was a clever invention. They said it was an obvious arrangement-which made him very cross. Said he would be within his rights to board every U.S. ship coming within the 3-mile limit and seize their tables by force. I do not think our Law would have sustained Percy in his view, but we would have liked to have got his permission to have used it, just to have kept everybody happy. To this end I visited him, the publishers visited him, and Captain Brown visited him. But although he was most charming as a host and full of interesting reminiscences, \&c., at the first mention of 'Haversine Table' he would 'out cutlasses and repel boarders'. We would have been willing to have paid him a small lump sum around the $f_{\text {I }}$ oo mark, but his ideas ran to a few thousand.

While these difficulties were still unsolved a yet greater, and apparently insuperable obstacle to progress developed. The publishers seemed to be losing interest. To my anxious soundings they replied that they still favoured the ultimate production of such a book, but there was no hurry. The 'times were not propitious'. They were too busy with other work, and so on. There was nothing much I could do about this. I was under agreement to them, but the Agreement contained no time clause, and such MSS and other material as I had completed 
was kept in their safes. Moreover, they were the only publishers capable of appreciating the possibilities of the book sufficiently to seriously consider financing its production. It seemed that the seven lean years of the project had set in.

Well, this might haye been the end. For a year or two I continued to work away at certain things, but the going seemed harder. Then suddenly and unexpectedly a turn of personal fortune changed everything and made it just possible that I might be able to produce the book at my own expense-if I could get free of the Agreement I was already committed to.

To their eternal credit, these first prospective publishers of the book granted me an unconditional release without hesitation and gave me all my stuff back. We have remained friends ever since and they have always been most helpful.

For a while after this I felt like a ship at sea without a compass. I knew no publishers and had no knowledge of the business of publishing. I only knew that anyone publishing a book at his own expense was regarded by the World in general and publishers in particular as-'a mut'.

Well, I had been told that in the publishing world there are many sharks. Perhaps there are. But if so $I$ must have been lucky. The first publishing firm with whom I opened negotiations insisted on my joining the Authors' Society so that I should have the benefit of their skilled legal advice if we got as far as drawing up an Agreement. I dealt with four firms before finally getting things fixed up, and I felt absolute confidence in the honesty and fairness of all of them. Perhaps if I had represented myself as a competent business man capable of keeping publishers in their place, it might have been different. But 1 always made it clear that on the business side I was an absolute 'greenhorn', and apparently it was not done by the best people in the trade to 'shoot an unarmed man'.

The first serious shock I had concerned the probable cost of production. The publishers I had approached did not seem to realize this at first themselves. It seemed that to type-set an average page of reading matter would cost (then) between 25 and 35 shillings, and in my first discussions with them they had supposed that this was such a case. But a day or two later they rang me up to come and see them, and then asked me if I had any idea what my book was likely to cost. Of course I said, in effect, 'No. You tell me'. Well they said, we make the cost of setting this stuff about $£_{5}$ a page! I confess to a sort of panicky feeling while I held my breath and did a quick mental calculation. Yes. At this rate it was going to cost over $£_{1000}$ to produce the first book. Question was, that even if this sum could be found, could a reasonable retail price be fixed which would not involve serious loss. It didn't look like it, but by way of playing for time I asked them to prepare a firm estimate for the first 1000 books : which they said I should have in a few days.

In due course it came along. 19s. per book plus is. for binding.

Now, the publishers advice was, that the selling price of a book should never be fixed at a price which would involve a loss on the first edition. I also knew that any publisher would want 50 per cent of the retail price as their selling expenses and profit. Cast-iron, closed shop rate. This meant a no-profit selling price of 4os. per book. Obviously hopeless! But during the discussions on these estimates yet another unpleasant bogey reared its head. It seemed that shortly after I had got the first edition into being (if ever) I should be faced with either rent of type at about $\mathcal{E}_{4} \circ$ annually, or the making of unalterable plates at about f 120 . The first edition, it was explained, would be in the form of some tons of 
type-metal. This is very expensive stuff, and printers only keep a limited stock of it. After a book is printed the type-metal is presently melted down and goes back into stock. If a book is intended to run to several impressions, plates would be made-unless, of course, it was some kind of ephemeris, or a lot of modifications are expected. I could see some really painful dilemmas arising out of this state of affairs. The book was bound to have a long struggle for recognition, and fairly sure to need modifications. The thought of being unable to find the necessary capital to keep the fight going and, in consequence, seeing the whole job literally shovelled back into the melting pot was something too painful to contemplate. I had now formed my own views as to why a new volume of nautical tables had not appeared for a hundred years!

Well, as we all know, the difficulties were got over: although not by any cleverness on my part, for luck came to my rescue. It happened this way.

The London publishers mentioned that they sometimes got printing done more cheaply by sending it out to the farther provinces: and they got me an estimate from-somewhere on the Welsh border, I think. This was still hopeless, but nevertheless substantially less than their London prices. But it reminded me that several years before I had submitted a page of tables to a firm which worked in the middle of Scotland, and that the price that they had quoted was somewhere about half these London quotations. Of course, I supposed that they had made the same mistake that the other publishers had made on first glancing over the job. However, I wrote away to them, asking them to re-examine their quotation and if possible confirm it. They did. Confirm it, I mean.

This sounded too good to be true. The firm were, of course, printers only: and so as the question of publishers would still arise I went along to consult George Philip, the publishers I had last dealt with. They said that although they could not possibly produce the book at that price, and could not imagine how anybody could, nevertheless, if I could get the book produced at that price, or any other price, they would be quite ready to act as publishers and distributors for me. So it was in a mood of cautious optimism that I set out for Scotlandand that optimism proved to be abundantly justified. The firm, of course, was Robert Cunningham \& Sons of Alva, near Stirling.

From now on it was a case of 'Happy days are here again'. Proof sheets soon began rolling in. There were to be three checks altogether. There would be about $95^{\circ}$ thousand figures. Pretty near the million! It was summertime, and I began rising at 5 a.m. each morning. No effort. Woke up itching to start work; although I won't go so far as to say that the itch kept up all day.

In due course the last stages were reached, and I went out and stayed at Alva to check the final sheets and see the first trial books folded and stitched. In the intervals, waiting for sheets to come up, I was able to climb up the worldfamous Alva Glen and look down across the sun-lit countryside. Truly, I felt the best of all Worlds to be at my feet. Not that I allowed myself to forget that the greatest struggle-the struggle for recognition-was only just about to begin.

It has had its ups and downs, this battle. It would not be fitting to say much about it here: but I will beg permission to mention one particular 'up', of which I was rather proud. It happened at one of the fiercest phases of the war when the enemy had temporarily cut our Mediterranean supply line. I received one day through the publishers a request from the Hydrographer of the Navy, saying that a shortage of my Nautical Tables had developed in the Eastern Medi- 
terranean, and requesting permission to reproduce certain parts of the book photographically in Egypt for use in the fleet. This, of course, was in the book's earlier days when it was still little known in the Merchant Navy.

\title{
Collision Regulations
}

\author{
from O. W. Neumark
}

Over a decade ago there was some controversy about the selection of an international standard airfield approach lighting system. At a very late stage, the R.A.E. produced a visual simulator of great simplicity on which any administrator could fly approaches using any of the rival systems. His performance could be checked but, what is far more important, he obtained personal and realistic visual experience. If this simulator had been available in 1945 it might have saved many millions spent on the flight evaluations of the rival systems and years of international conferences.

In the present controversy on collision avoidance regulations in the air and at sea, time and wealth could be saved by the creation of a visual and dynamic simulator in which all persons attending symposiums on collision problems could obtain synthetic visual experience of the present day avoidance regulations and of the new conventions proposed by E. S. Calvert and S. H. Hollingdale.

Curiously enough, such a simulator would not be very costly. It would consist of a very large hangar and a number of small electric two-seater cars somewhat similar to those known as 'Dodgems' often seen at Funfairs.

It would be used quite effectively for simulating air traffic as a high percentage of all near-misses occur in the horizontal plane but it would be desirable to gimbal the cars so that they can bank when turning.

Simulation of nocturnal traffic requires only black-out and navigation lights. Day traffic simulation would require painting the floor, walls, ceiling and cars in the same paint scheme to obliterate all detail except for miniature replicas of ships or aircraft on each car. Two-colour filter systems might be even cheaper and more effective.

The essential function of the simulator would be to 'test' the effectiveness of different collision avoidance conventions by direct visual experience without risk.

Multi-body problems, restricted waters, special cases, non-standard navigation and anti-collision lights could all be experienced. Pilot controlled visual collision course beam attacks could be practised.

Such a simulator would be an extremely useful addition to the next symposium on collision problems.

It should be noted that such a 'conference' simulator is in a completely different category to multi-position radar PPI simulators which are essential for training radar navigators and air-traffic controllers.

8* 